\title{
Accelerometer Quantification of Physical Activity and Activity Patterns in Patients with Ankylosing Spondylitis and Population Controls
}

Citation for published version (APA):

van Genderen, S., Boonen, A., van der Heijde, D., Heuft, L., Luime, J., Spoorenberg, A., Arends, S., Landewé, R., \& Plasqui, G. (2015). Accelerometer Quantification of Physical Activity and Activity Patterns in Patients with Ankylosing Spondylitis and Population Controls. Journal of Rheumatology, 42(12), 23692375. https://doi.org/10.3899/jrheum.150015

Document status and date:

Published: 01/11/2015

DOI:

10.3899/jrheum.150015

Document Version:

Publisher's PDF, also known as Version of record

Document license:

Taverne

Please check the document version of this publication:

- A submitted manuscript is the version of the article upon submission and before peer-review. There can be important differences between the submitted version and the official published version of record.

People interested in the research are advised to contact the author for the final version of the publication, or visit the DOI to the publisher's website.

- The final author version and the galley proof are versions of the publication after peer review.

- The final published version features the final layout of the paper including the volume, issue and page numbers.

Link to publication

\footnotetext{
General rights rights.

- You may freely distribute the URL identifying the publication in the public portal. please follow below link for the End User Agreement:

www.umlib.nl/taverne-license

Take down policy

If you believe that this document breaches copyright please contact us at:

repository@maastrichtuniversity.nl

providing details and we will investigate your claim.
}

Copyright and moral rights for the publications made accessible in the public portal are retained by the authors and/or other copyright owners and it is a condition of accessing publications that users recognise and abide by the legal requirements associated with these

- Users may download and print one copy of any publication from the public portal for the purpose of private study or research.

- You may not further distribute the material or use it for any profit-making activity or commercial gain

If the publication is distributed under the terms of Article $25 \mathrm{fa}$ of the Dutch Copyright Act, indicated by the "Taverne" license above, 


\title{
Accelerometer Quantification of Physical Activity and Activity Patterns in Patients with Ankylosing Spondylitis and Population Controls
}

\author{
Simon van Genderen, Annelies Boonen, Désirée van der Heijde, Liesbeth Heuft, Jolanda Luime, \\ Anneke Spoorenberg, Suzanne Arends, Robert Landewé, and Guy Plasqui
}

\begin{abstract}
Objective. To compare the total amount of physical activity (TPA) and time spent in various activity intensities of patients with ankylosing spondylitis (AS) and population controls, and to explore factors related to physical activity (PA).

Methods. Subjects were asked to wear a triaxial accelerometer for 7 days and to complete a series of questionnaires. Multivariable regressions were used to assess generic determinants of TPA in patients and controls, and in patients to explore demographic and disease-specific determinants of various PA intensities.

Results. One hundred and thirty-five patients [51 $\pm 13 \mathrm{yrs}, 60 \%$ men, body mass index (BMI) $26.0 \pm$ $4.3 \mathrm{~kg} / \mathrm{m}^{2}$ ] and 99 controls $\left(45 \pm 12 \mathrm{yrs}, 67 \%\right.$ men, BMI $\left.25.1 \pm 4.3 \mathrm{~kg} / \mathrm{m}^{2}\right)$ were included. Patients did not differ from controls regarding TPA (589 vs 608 vector count $/ \mathrm{min}, \mathrm{p}=0.98)$, minutes/day spent in sedentary ( 524 vs 541, p = 0.17), and light PA (290 vs $290 \mathrm{p}=0.95)$, but spent fewer minutes/day in moderate to vigorous PA (MVPA; 23 vs $30 \mathrm{~min} / \mathrm{day}, \mathrm{p}=0.006$ ). Perceived functional ability (physical component summary of the Medical Outcomes Study Short Form-36) and BMI were associated with TPA independent of having AS (p interaction $=0.21$ and 0.94 , respectively). Additional analyses in patients showed that time spent in MVPA was negatively influenced by BMI, physical function (Bath AS Functional Index), and disease duration. In patients $\geq 52$ years old, a higher Bath AS Disease Activity Index was associated with less time spent in sedentary and more time spent in light activities.

Conclusion. Compared with controls, patients with AS had similar TPA, but may avoid engagement in higher intensities of PA. Lower levels of functional ability and higher BMI were associated with lower TPA in both patients and controls. (First Release November 1 2015; J Rheumatol 2015; 42:2369-75; doi:10.3899/jrheum.150015)
\end{abstract}

Key Indexing Terms: PHYSICAL ACTIVITY ANKYLOSING SPONDYLITIS

ACCELEROMETER ACTIVITY PATTERNS REPORTED OUTCOMES

Regular physical activity (PA) has well-known beneficial health effects. Moderate and vigorous intensities of PA (MVPA) are especially considered vital to enhance health ${ }^{1,2}$.
Research in the overall population has shown clear positive effects of MVPA on health. A recent population study in 217,755 middle-aged adults indicated that time spent in
From the Department of Internal Medicine, Division of Rheumatology, Maastricht University Medical Center+, Maastricht; Caphri Research Institute, Maastricht University, Maastricht; Rheumatology, Leiden University Medical Center, Leiden; Rheumatology, Sint Laurentius Hospital Roermond and Sint Jans Gasthuis Weert, Roermond and Weert; Rheumatology, Sint Laurentius Hospital Roermond, Roermond; Rheumatology, Erasmus Medical Center Rotterdam, Rotterdam; Rheumatology and Clinical Immunology, University of Groningen, University Medical Center Groningen, Groningen; Rheumatology, Medical Center Leeuwarden, Leeuwarden; Rheumatology, Amsterdam Medical Center; Rheumatology, Atrium Medical Center, Amsterdam, the Netherlands.

Unrestricted financial support for an investigator-initiated study provided by AbbVie b.v.

S. van Genderen, MSc, Department of Internal Medicine, Division of Rheumatology, Maastricht University Medical Center+, and Caphri Research Institute, Maastricht University; A. Boonen, $M D, P h D$, Professor, Department of Internal Medicine, Division of Rheumatology, Maastricht University Medical Center+, and Caphri Research Institute,
Maastricht University; D. van der Heijde, MD, PhD, Professor, Rheumatology, Leiden University Medical Center; L. Heuft, MD, PhD, Rheumatology, Sint Laurentius Hospital Roermond, and Sint Jans Gasthuis Weert; J. Luime, PhD, Rheumatology, Erasmus Medical Center Rotterdam; A. Spoorenberg, $M D, P h D$, Rheumatology and Clinical Immunology, University of Groningen, University Medical Center Groningen, and Rheumatology, Medical Center Leeuwarden; S. Arends, $P h D$, Rheumatology and Clinical Immunology, University of Groningen, University Medical Center Groningen, and Rheumatology, Medical Center Leeuwarden; R. Landewé, MD, PhD, Professor, Rheumatology, Amsterdam Medical Center, and Rheumatology, Atrium Medical Center; G. Plasqui, PhD, Human Biology, Maastricht University Medical Centre+.

Address correspondence to S. van Genderen, Department of Internal Medicine, Division of Rheumatology, Maastricht University Medical Center+, Prof. Debyelaan 25, 6202 AZ Maastricht, the Netherlands. E-mail: s.vangenderen@maastrichtuniversity.nl

Accepted for publication August 27, 2015.

Personal non-commercial use only. The Journal of Rheumatology Copyright @ 2015 . All rights reserved. 
vigorous intensity of PA, independent of the total amount of PA, was associated with a reduced risk of mortality ${ }^{3}$. Patients with ankylosing spondylitis (AS) can be hampered in their daily habitual activities because of pain, stiffness, and limitations in mobility ${ }^{4,5}$. It might therefore not be straightforward for patients to engage in sufficient PA to maintain or improve health. In AS, the literature on the total amount of physical activity (TPA), representing all measured movement of the body produced by skeletal muscle ${ }^{6}$, as well as time spent in different intensities of movement, is scarce and contrasting. When using an objective measure to assess PA, evidence of 2 studies examining a small group of patients with $\mathrm{AS}^{7}$ or axial spondyloarthritis (axSpA $)^{8}$ shows that patients have a similar or slightly lower level of TPA than healthy controls, respectively. Regarding time spent in different levels of intensity, patients with axSpA were shown to spend less time in MVPA in comparison with controls ${ }^{8}$. However, in a study based on a validated recall questionnaire to assess PA, it was reported that patients with $\mathrm{SpA}$, including AS, more often than healthy controls met the recommendations of the World Health Organization (WHO $)^{9}$, i.e., 150 min of PA a week in moderate intensity, 60-75 $\mathrm{min}$ in vigorous intensity, or an equivalent combination of both ${ }^{2,10}$. Additional data are needed to elucidate these contradicting findings and to see whether findings such as meeting the WHO recommendations remain once PA is objectively measured.

When aiming at optimizing PA in patients with AS, it is important to understand factors contributing to PA and to explore whether such factors would be different in patients compared with healthy individuals. This is relevant because it might reveal that patients require different approaches to optimize PA and no such data are available. Among patients, the limited cross-sectional evidence suggests that higher levels of PA are associated with lower disease activity and better spinal mobility, physical function, and health-related quality of life, as well as lower levels of C-reactive protein (CRP) and erythrocyte sedimentation rate (ESR) $7,9,11,12,13$. On the other hand, data have been reported that heavy loading jobs can accelerate spinal radiographic damage ${ }^{14}$. A first step to elucidate these relevant issues is to explore PA and its patterns in patients with AS.

Therefore, given the previously mentioned gaps in knowledge, the primary aim of our current study was to compare TPA as well as time spent in different intensities of PA in patients with AS and population controls using validated accelerometers. Secondary aims were first to study whether known determinants of PA such as difficulties in functional ability and a higher body mass index (BMI) have a similar influence on the TPA in patients and controls, and next to investigate the association between disease-specific determinants and time spent in various intensities of PA in patients with AS. It was hypothesized that patients would not differ from controls regarding total performed PA, but would spend less time in MVPA.

\section{MATERIALS AND METHODS}

The Social Participation in AS Study (SPASS) was a multicenter crosssectional study that first aimed to assess social role participation in an online questionnaire survey and second to investigate objectively assessed PA in patients with AS compared with population controls in a random subsample for whom an accelerometer was available. The study protocol was approved by the ethics committee of the academic hospital Maastricht and Maastricht University.

Patients. Patients of at least 18 years, registered with a diagnosis of AS in each of the 6 participating rheumatology departments and for whom the rheumatologist confirmed they fulfilled the modified New York criteria for AS, were invited by a letter. Patients were excluded if they had no access to the Internet or were not familiar with the Dutch language. Figure 1 illustrates that 246 of a total of 740 patients with AS (33\%) consented to participate in the SPASS study. Of a random sample, 154 also participated in our current substudy on PA. All patients provided written informed consent.

Controls. Control subjects were recruited from a national open online panel of the research institute Ipsos (Amsterdam, the Netherlands). Based upon our expectations of a cross-sectional sample in AS, the population controls were sampled to have an average age of 42 years and a male:female distribution of $3: 1^{15}$. Subjects were excluded if they had any musculoskeletal disorders or if they were not familiar with the Dutch language ${ }^{16}$. Figure 1 shows that of the 510 of a total of 2767 controls (18\%) who participated in the online questionnaire survey, a randomly selected subgroup $(n=109)$ agreed to wear the triaxial accelerometer.

Assessments. PA was measured using a triaxial accelerometer (Actigraph GT3X, Actigraph LLC Pensacola), which had shown good validity when using energy expenditure measured by doubly labeled water as the gold standard ${ }^{17}$. It was attached at the lower back of the subject by means of an elastic belt and measured minute by minute accelerations (expressed as counts) in the anteroposterior, mediolateral, and longitudinal axes of the trunk. Subjects received the accelerometer by mail and were instructed to wear the device for 7 consecutive days during waking hours, except during water activities. Data were considered to be complete if subjects wore the accelerometer for at least 3 days and $10 \mathrm{~h}$ per day. In addition, whenever the device measured consecutive zeroes over a period of $\geq 60 \mathrm{~min}$, this was classified as a non-wear period. From the output of the 3 axes, the vector magnitude counts $\left(\mathrm{VM}^{3}\right)$ could be calculated $\left[\mathrm{VM}^{3}=\sqrt{ }\left(\right.\right.$ total counts axis $1^{2}$ + total counts axis $2^{2}+$ total counts axis $\left.3^{2}\right)$, and subsequently counts per day $\left(\mathrm{CPD}=\mathrm{VM}^{3} \div\right.$ total wear time in calendar days $)$ and counts per minute $\left(\mathrm{CPM}=\mathrm{VM}^{3} \div\right.$ total wear time in minutes $)$. For categorizing accelerometer data into different intensities of PA, Troiano cutoff values were used to calculate the number of minutes spent in sedentary (0-99 CPM), light (100-2019 CPM), moderate (2020-5998 CPM), or vigorous PA ( $\geq 5999$ $\mathrm{CPM})^{18}$. As a result, average minutes spent per day in each intensity could be calculated as follows: total minutes (intensity) $\div$ total wear time in calendar days. Using the average minutes spent in MVPA per day, subjects who met the WHO recommendations could be identified.

Questionnaire and measures. Questions on socioeconomic background and lifestyle consisted of information about sex, age, and highest finished educational degree, as well as weight and height. To assess generic health, the Medical Outcomes Study Short Form-36 (SF-36) was included. The SF-36 assesses difficulties attributable to mental or physical health across 8 domains: social function, physical function, bodily pain, role physical, role emotional, general health, vitality, and mental health. From the domains, 2 summary scores can be calculated: the physical component summary (PCS) and the mental component summary (MCS), ranging from 0 to 100 (higher scores reflecting better health) ${ }^{19,20}$

To assess aspects of AS-related health, patients indicated their diagnosis duration (time since diagnosis, in yrs) and completed the Bath AS Disease Activity Index (BASDAI) and the Bath AS Functional Index (BASFI) ${ }^{21,22}$ Finally, information about the current use of medication, i.e., use of tumor necrosis factor- $\alpha$ blocking therapy, was obtained.

Statistics. All analyses were performed with PASW Statistics 20 (SPSS). 


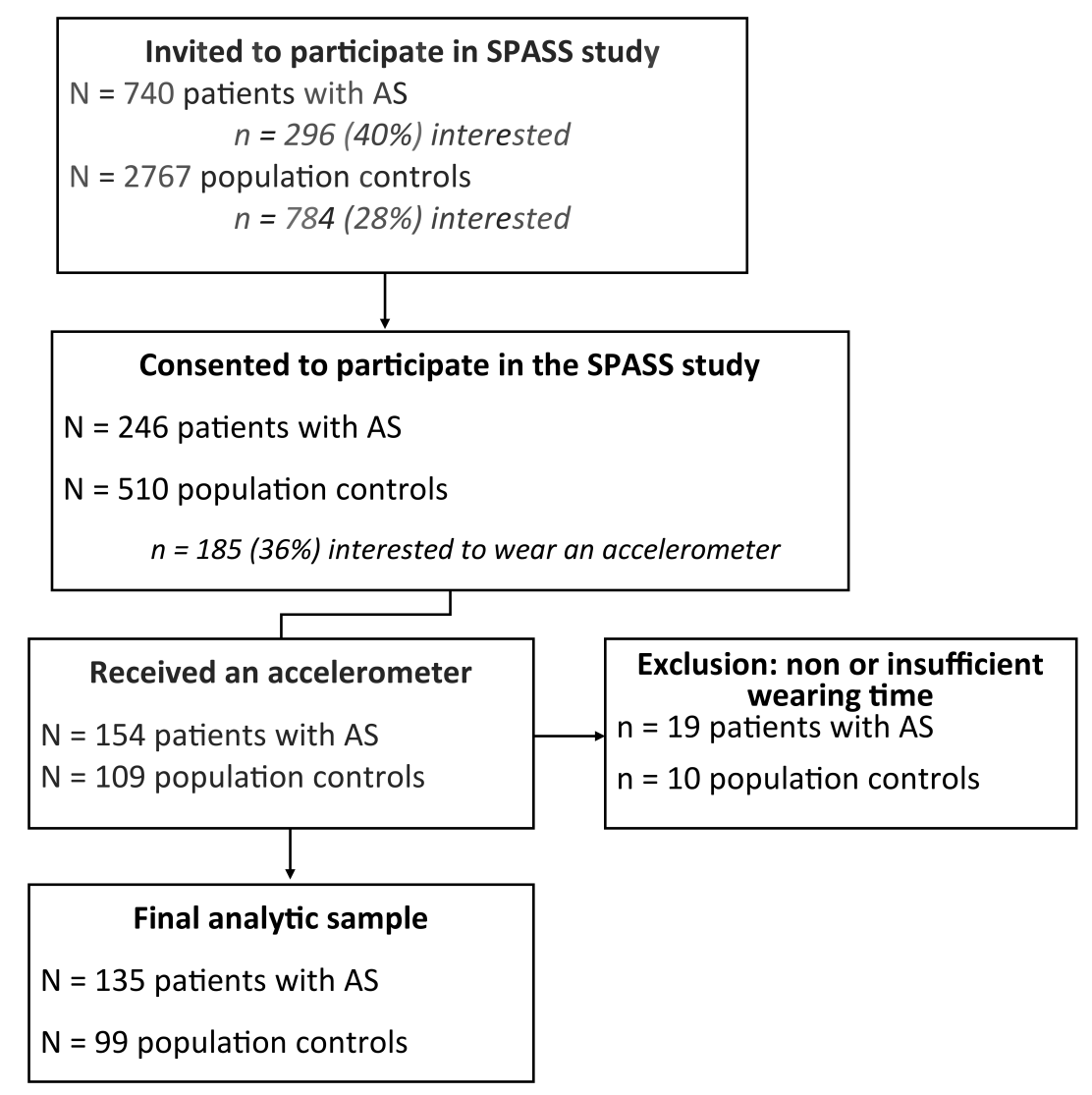

Figure 1. Subjects flowchart. AS: ankylosing spondylitis; SPASS: Social Participation in AS Study.

After checking normality of the data, comparisons between patients and controls were performed with independent Student $t$ tests or Kruskal-Wallis test (SF-36 PCS, MCS, calendar days the accelerometer was worn, and time active in MVPA). To adjust the comparisons of the different accelerometer outputs between patients and controls for multiple comparisons, the Benjamini-Hochberg procedure was performed using a false discovery rate of $20 \%{ }^{23}$. Given the relatively low amount of time spent in vigorous PA, these minutes were combined with the time spent in moderate PA for further analyses. When exploring the differences between patients and controls in TPA (CPM) or the time spent in various intensities of PA, linear regressions were used to adjust for possible differences in age, sex, and BMI between both groups.

Multivariable regression was also used in an explanatory model to assess whether the effect of generic functional abilities (SF-36 PCS) and BMI on TPA was independent of age, sex, and having a diagnosis of AS. Linearity was checked as well as possible interactions of groups with BMI, PCS, age, and sex.

Finally, to understand the influence of disease-related variables on minutes spent in sedentary, light, and (square root transformed) MVPA in patients with AS, multivariable regression analysis was performed with age, sex, BMI, diagnosis duration, BASDAI, and BASFI as potential determinants. Because minutes spent in MVPA were slightly skewed, the variable was square root transformed. $\mathrm{P}$ values $\leq 0.05$ were considered statistically significant.

\section{RESULTS}

Samples. The final sample consisted of 135 patients with AS and 99 population controls (Figure 1). The characteristics of both patients and controls are presented in Table 1. Patients were older and had a worse self-reported physical health (SF-36) in comparison with population controls.

$P A$ at different intensities in patients with AS and population controls. The median (interquartile range) of the number of calendar days patients wore the accelerometer was 7 (6-7) days and for controls 7 (7-8) days. Patients with AS did not differ from controls regarding the TPA expressed in CPM (Table 2), not even after adjusting for age, sex, and BMI. Regarding the sum of time spent in all different intensities, which was also equivalent to the total wearing time in minutes, the population controls registered on average 25 $\mathrm{min} /$ day more activity than patients $(\mathrm{p}=0.01)$. This difference could be attributed mainly to more time (17 $\mathrm{min}$ /day) in sedentary activity by controls, although this was not statistically significant. The time spent in light activities was the same in both groups. Patients spent 7 fewer minutes a day in MVPA $(p=0.006)$ compared with controls, which resulted in a lower percentage of patients meeting the norm of $150 \mathrm{~min}$ of at least moderate PA a week $(46.7 \%$ vs $59.6 \%$ in controls, $p=0.05$ ). In addition, the findings between groups remained significant after correcting for the false discovery rate and did not change after controlling for age, sex, and BMI. 
Table 1. Demographic and health characteristics of the patients with AS and population controls. Values are mean (SD) [minimum-maximum] unless otherwise specified.

\begin{tabular}{lccc}
\hline Characteristic & Patients with AS, $\mathrm{n}=135$ & Controls, $\mathrm{n}=99$ & $\mathrm{p}$ \\
\hline Age, yrs & $51(13)[24-79]$ & $45(12)[23-84]$ & $<0.001$ \\
Males & $81(60)$ & $66(67)$ & 0.34 \\
Education, at least 12 yrs & $118(87)$ & $86(87)$ & 0.90 \\
Employed, n (\%) & $78(58)$ & $84(85)$ & $<0.001$ \\
BMI, kg/m & $26.0(4.3)[17.0-41.8]$ & $25.1(4.3)[16.8-47.7]$ & 0.09 \\
Diagnosis duration, yrs & $16.5(12.1)[0-61]$ & - & - \\
BASDAI, 0-10 & $4.3(2.2)[0-9.5]$ & - & - \\
BASFI, 0-10 & $4.1(2.6)[0-10]$ & - & - \\
Biological medication, $\mathrm{n}(\%)$ & $69(51)$ & - & - \\
SF-36 PCS, 0-100 & $38.8(10.7)[9.9-61.9]$ & $55.7(6.0)[24.1-69.5]$ & $<0.001$ \\
SF-36 MCS, 0-100 & $50.2(12.7)[10.9-70.5]$ & $52.2(8.7)[20.1-63.2]$ & 0.99 \\
\hline
\end{tabular}

AS: ankylosing spondylitis; BMI: body mass index; BASDAI: Bath Ankylosing Spondylitis Disease Activity Index; BASFI: Bath Ankylosing Spondylitis Functional Index; SF-36: Medical Outcomes Study Short Form-36; PCS: physical component summary; MCS: mental component summary.

Table 2. Results of total PA and time spent in different intensities of PA as assessed by the 7-day accelerometer registration, separately for patients with AS and population controls. Values are mean (SD) [minimum-maximum] unless otherwise specified.

\begin{tabular}{lcccc}
\hline Variable & Patient with AS, $\mathrm{n}=135$ & Controls, $\mathrm{n}=99$ & $\mathrm{p}$ & $\mathrm{p} *$ \\
\hline $\mathrm{VM}^{3}$, counts/min & $589(202)[157-1158]$ & $608(219)[150-1465]$ & 0.98 & 0.86 \\
$\mathrm{VM}^{3}$, counts/day & $492,400(173,511)$ & $521,847(178,955)$ & & \\
& {$[116,773-932,839]$} & {$[126,538-1,025,867]$} & 0.21 & 0.245 \\
Time active, min/day & $837(77)[646-1058]$ & $862(68)[647-993]$ & 0.01 & 0.04 \\
$\quad$ Sedentary, min/day & $524(99)[279-783]$ & $541(94)[247-751]$ & 0.17 & 0.238 \\
Light intensity, min/day & $290(86)[40-520]$ & $290(74)[80-462]$ & 0.95 & 0.86 \\
$\quad$ Moderate intensity, min/day & $22(18)[0-122]$ & $28(20)[4-109]$ & 0.02 & 0.05 \\
Vigorous intensity, min/day, & & & & \\
total n $(\%)=30(22)$ & $1(4)[0-22]$ & $2(5)[0-32]$ & $<0.001$ & 0.01 \\
At least 150 min of MVPA a week, & & & & \\
$\mathrm{n}(\%)$ & $63(46.7)$ & $59(59.6)$ & 0.05 & - \\
\hline
\end{tabular}

* P value is the Benjamini-Hochberg adjusted p value for multiple comparisons. AS: ankylosing spondylitis; PA: physical activity; $\mathrm{VM}^{3}$ : vector magnitude counts $=\sqrt{ }\left(\right.$ total counts axis $1^{2}+$ total counts axis $2^{2}+$ total counts axis $3^{2}$ ); MVPA: moderate to vigorous PA.

Association between total PA and possible determinants in patients with $A S$ and controls. In the multivariable analyses on TPA (CPM), the age, male sex, and group (having AS) were not significant contributors. Better self-reported functional ability was associated with more TPA $(\beta 4.3, p=$ $0.005)$. For every point the PCS of the SF-36 increased, TPA increased 4.3 CPM. In addition, a higher BMI was associated with less TPA ( $\beta-7.9, p=0.01)$, indicating that every point increase in the BMI was associated with a decrease in TPA of 7.9 CPM. There were no significant interactions between group and any of the other variables.

Determinants of various intensities of PA in patients with AS. In the multivariable models with minutes spent in sedentary PA and light PA as dependent variables, a significant interaction effect of age and BASDAI was found and consequently the regression models were stratified for age (at the median of $52 \mathrm{yrs})$. In patients aged under 52 years $(\mathrm{n}=66$,
$56 \%$ men), a higher BMI was associated with more time per week spent in sedentary PA ( $\beta$ 8.6, p $=0.007$; Table 3$)$. In contrast, patients 52 years or older $(n=69,64 \%$ men), being male $(\beta 45.6, p=0.04)$, and having a higher BMI $(\beta 5.6, p=$ 0.02 ) were associated with more time spent in sedentary PA. In addition, the same analyses showed that a lower BASDAI was associated with less time spent in sedentary PA ( $\beta-20.7$, $p=0.006)$. Regarding the analyses with time spent in light PA (Table 3), none of the entered explanatory variables were contributory in the group of patients of $<52$ years. In the group of patients $\geq 52$ years, a significant association with higher BASDAI and more time in light PA was found ( $\beta$ $14.61, p=0.04)$. Of note, the sum of total time spent within all activity intensities did not differ between the strata of patients older and younger than 52 years $(\mathrm{p}=0.80)$.

Finally, no interactions were observed when exploring the time spent in the square rooted MVPA. In the model (Table 
Table 3. Results of the multivariable regressions investigating the association of several explanatory factors and minutes spent in sedentary, light, and MVPA per day in patients with ankylosing spondylitis.

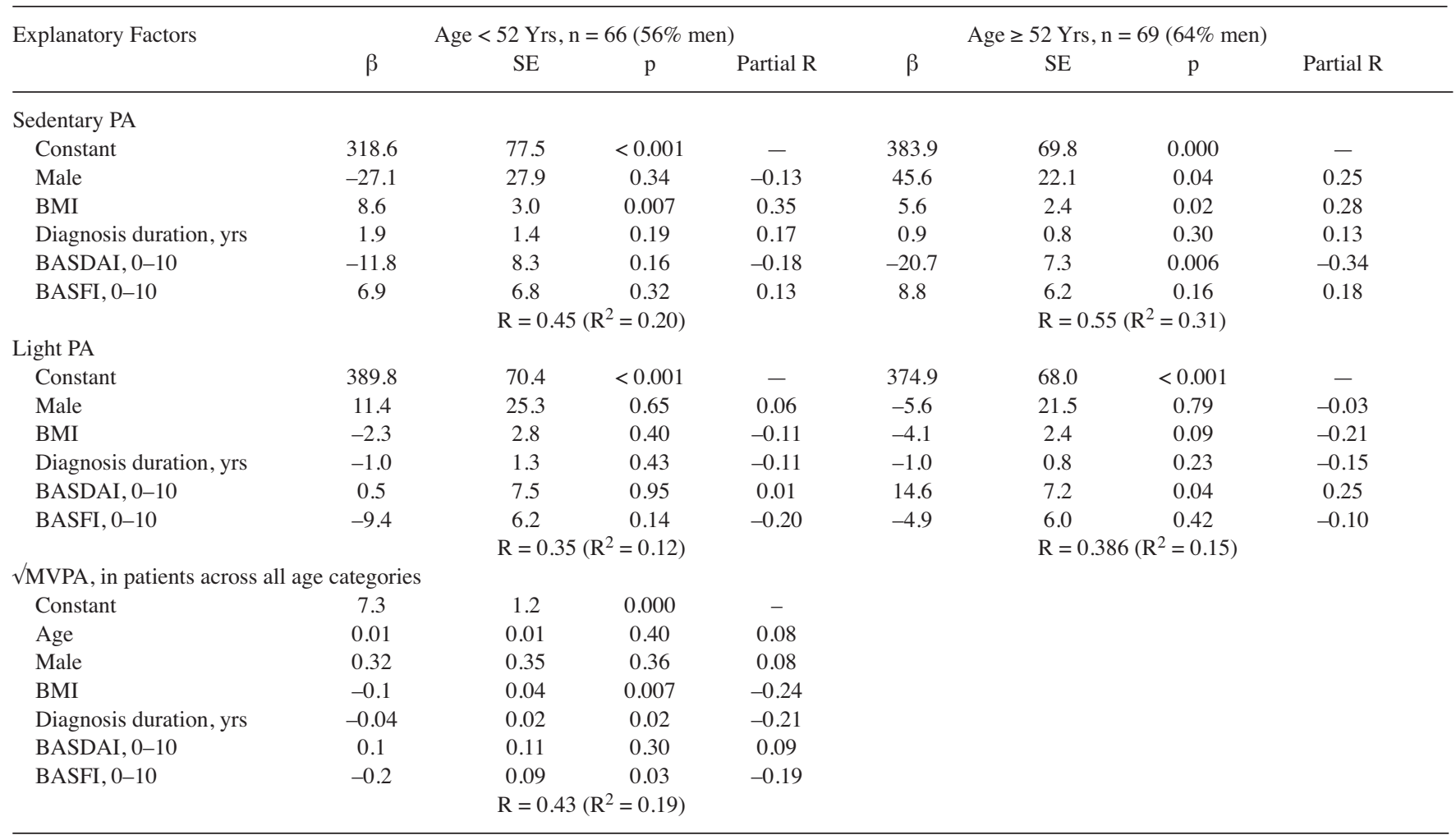

PA: physical activity; MVPA: moderate to vigorous PA; BMI: body mass index; BASDAI: Bath Ankylosing Spondylitis Disease Activity Index; BASFI: Bath Ankylosing Spondylitis Functional Index.

$3)$, negative associations with higher BMI ( $\beta-0.01, \mathrm{p}=$ $0.007)$, longer diagnosis duration $(\beta-0.04, p=0.02)$, and higher BASFI $(\beta-0.2, p=0.03)$ were observed.

\section{DISCUSSION}

The findings of our study confirmed our hypothesis that patients with AS did not differ from population controls in the total amount of objectively measured PA, but spent less time in MVPA. Further explorations revealed that the negative influence of impaired functional ability and BMI on TPA was similar in patients as in controls. Among patients, increased BMI, diagnosis duration, and BASFI, but not reported disease activity, reduced the time spent in MVPA. Remarkably, in older patients, a higher disease activity was associated with less time spent in sedentary but more time spent in light intensities of PA.

When interpreting the current findings from the perspective of existing literature, it should be noted that different assessment tools are used, and in comparison with objective accelerometers, retrospective self-reports are hampered by the possible overestimation of PA because of recall bias ${ }^{24}$.

Our findings on TPA assessed with an accelerometer are in agreement with Plasqui, et al, who also found no differ- ences in a much smaller group of 48 patients with AS and controls ${ }^{13}$. In contrast, a study by Swinnen, et al $(\mathrm{n}=80)$ concluded that, in total, activity of patients with axSpA was lower compared with controls. However, in that study, both patients [median PA level (PAL) of 1.45] and controls (median PAL of 1.54) had a remarkably low PAL in comparison with reference values found in the general population (mean PAL 1.7), indicating that care should be taken when interpreting these results 8,25 . For referencing, the study by Plasqui, et al found a mean PAL of 1.73 in patients with AS and 1.74 in controls, results in line with reference values as measured in the general population ${ }^{13}$.

As for time spent in different intensities of PA, patients in our study spent less time in more vigorous intensities of PA, which was in line with the additional results of the study by Swinnen, $e t \mathrm{al}^{8}$. When considering the proportion of patients complying to the current $\mathrm{WHO}$ recommendations as assessed by a validated recall questionnaire, Haglund, et $a l^{9}$ reported that $68 \%$ of 2126 patients with SpA complied with these recommendations (reflecting at least moderate PA) ${ }^{2}$, which was slightly better than the proportion reported from the general population ${ }^{9}$. Using an accelerometer, we found that only $47 \%$ of the patients and $60 \%$ of the directly compared controls reached this level. Validated recall questionnaires

Personal non-commercial use only. The Journal of Rheumatology Copyright @ 2015 . All rights reserved. 
are regarded as more practical for clinical use, yet the selection of commercially available accelerometers and activity monitors is rapidly increasing ${ }^{26}$, which might provide opportunities for a more extensive use of these devices in future research.

Regarding factors contributing to the TPA in patients and controls, the negative effect of BMI was apparently not amplified in patients. In the general population, it is known that overweight (BMI $\geq 25 \mathrm{~kg} / \mathrm{m}^{2}$ ) is associated with lower $\mathrm{PA}^{27}$. Moreover, in AS it was shown that overweight relates to poorer perceptions about the benefits of exercise and provides a greater awareness of the barriers to exercise ${ }^{28}$. Overweight and/or perceptions of overweight may hamper PA engagement ${ }^{29,30}$, and seemingly this effect is the same in controls as in patients. Among similar lines, no group differences were observed with regard to functional ability measured by the SF-36 PCS, which was associated with less TPA. Although the interaction between the group variable with SF-36 PCS was not significant, the SF-36 PCS in the control group was distributed in a clustered pattern (i.e., controls did not experience functional problems), whereas a broader distribution over the range of functional ability was observed in patients. For this reason, the absence of a significant group effect should be interpreted with some caution.

Within patients, BMI, limitations in physical function (BASFI), and an increasing diagnosis duration were associated with reduced MVPA. The reduced time in MVPA within patients was previously confirmed by Prince, et al, who interviewed 52 patients with AS and confirmed that patients reported a decline in both time and intensity in sports and recreational PA participation after diagnosis ${ }^{31}$. The independent influence of diagnosis duration might be relevant to accumulate radiographic damage in AS and likely independently affects physical function and thus engagement in $\mathrm{PA}^{5,32}$. However, the BASDAI was not independently relevant for time spent in MVPA. We found that in older patients, but not younger patients, an increase in the BASDAI was significantly associated with less time spent in sedentary PA and also with more time spent in light intensity PA. The availability of more leisure time to be physically active is not a likely explanation because in both age groups, a similar number of patients had paid work. Apparently, older patients have experienced more than younger patients that light intensities of PA, such as walking and mild stretching, have beneficial effects on their functioning and well-being, despite somewhat more pain and stiffness ${ }^{33}$. Contrasting results can be found in a questionnaire study in which 78 patients with AS with a higher disease activity (mean age 51.4 yrs) reported a lower amount of TPA and spent less time in walking and vigorous intensity activities than patients with a lower disease activity (mean age $46.9 \mathrm{yrs})^{12}$. In our study, patients with a BASDAI $\geq 4$ did not differ regarding the total PA or intensities of PA compared with patients with a BASDAI $<4$.
Regular exercise is proposed by the Assessment of SpondyloArthritis international Society and European League Against Rheumatism recommendations as part of the nonpharmacological treatment of $\mathrm{AS}^{34}$. Activities of a higher intensity as some forms of exercise have known beneficial health effects, including cardiovascular risk factors ${ }^{35}$. Since our results revealed that patients spent less time in more vigorous intensities of PA than controls, more emphasis should be given to exercise programs that do not concentrate only on stretching and postural correction, but also on higher intensities of PA, especially because novel evidence in another study indicated that in healthy middle-aged adults, PA of vigorous intensity was related to declined risk of mortality ${ }^{3}$. While we call for more engagement in MVPA in patients with AS, we also need to admit that more research is needed on whether such activity would be beneficial for all patients in all stages of their disease. Another recent study found that in patients who were blue-collar workers, a surrogate for more PA, radiographic progression of spinal damage was significantly higher compared with white-collar workers ${ }^{14}$. However, it is unclear whether this depended on the type of vigorous physical activities; the type of overall health benefits is also uncertain. Yet differences in radiographic progression were small and likely positive effects of PA will outweigh these small differences, but more research is needed on this aspect.

Some limitations need to be addressed. Because of the cross-sectional design of our study, statements about causality of relationships cannot be drawn.

Further, we did not examine inflammation markers such as $\mathrm{CRP}$ and ESR, and therefore were unable to investigate the role of objective disease activity on the PA of patients. While the inclusion of the control group was a strong point of our study, we were not able to fully match the control population to the age and sex of the AS group, but none of these variables contributed to the measured PA outcomes and were controlled for in all further analyses. Moreover, the recruitment of both patients and controls to wear an accelerometer was voluntary, which could have led to selection bias based on motivation to wear an accelerometer. However, this applied to both patients and controls so that any bias likely affected both groups, preserving internal validity.

Patients with AS performed the same TPA as population controls, but spent less time in MVPA. Higher BMI, impaired physical function, and a longer diagnosis duration are the main factors hampering engagements in MVPA in patients having AS.

\section{REFERENCES}

1. World Health Organization. The World Health Report 2002: reducing risk, promoting healthy life. [Internet. Accessed September 28, 2015.] Available from: www.who.int/whr/2002/en/whr02_en.pdf

2. World Health Organization. Global recommendations on physical activity for health. [Internet. Accessed September 28, 2015.] Available from:

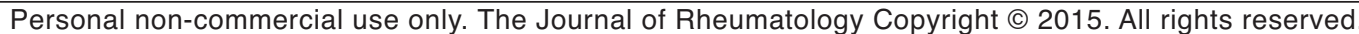


whqlibdoc.who.int/publications/2010/9789241599979_eng.pdf

3. Gebel K, Ding D, Chey T, Stamatakis E, Brown WJ, Bauman AE. Effect of moderate to vigorous physical activity on all-cause mortality in middle-aged and older Australians. JAMA Intern Med 2015;175:970-7.

4. Boonen A, vander Cruyssen B, de Vlam K, Steinfeld S, Ribbens C, Lenaerts J, et al. Spinal radiographic changes in ankylosing spondylitis: association with clinical characteristics and functional outcome. J Rheumatol 2009;36:1249-55.

5. Landewé R, Dougados M, Mielants H, van der Tempel H, van der Heijde D. Physical function in ankylosing spondylitis is independently determined by both disease activity and radiographic damage of the spine. Ann Rheum Dis 2009;68:863-7.

6. Caspersen CJ, Powell KE, Christenson GM. Physical activity, exercise, and physical fitness: definitions and distinctions for health-related research. Public Health Rep 1985;100:126-31.

7. van Genderen $S$, van den Borne C, Geusens $P$, van der Linden $S$, Boonen A, Plasqui G. Physical functioning in patients with ankylosing spondylitis: comparing approaches of experienced ability with self-reported and objectively measured physical activity. J Clin Rheumatol 2014;20:133-7.

8. Swinnen TW, Scheers T, Lefevre J, Dankaerts W, Westhovens R, de Vlam K. Physical activity assessment in patients with axial spondyloarthritis compared to healthy controls: a technology-based approach. PloS One 2014;9:e85309.

9. Haglund E, Bergman S, Petersson IF, Jacobsson LT, Strömbeck B, Bremander A. Differences in physical activity patterns in patients with spondylarthritis. Arthritis Care Res 2012;64:1886-94.

10. Garber CE, Blissmer B, Deschenes MR, Franklin B, Lamonte MJ, Lee IM, et al; American College of Sports Medicine. American College of Sports Medicine position stand. Quantity and quality of exercise for developing and maintaining cardiorespiratory, musculoskeletal, and neuromotor fitness in apparently healthy adults: guidance for prescribing exercise. Med Sci Sports Exerc 2011:43:1334-59.

11. Arends S, Hofman M, Kamsma YP, van der Veer E, Houtman PM, Kallenberg CG, et al. Daily physical activity in ankylosing spondylitis: validity and reliability of the IPAQ and SQUASH and the relation with clinical assessments. Arthritis Res Ther 2013;15:R99.

12. Fongen C, Halvorsen S, Dagfinrud H. High disease activity is related to low levels of physical activity in patients with ankylosing spondylitis. Clin Rheumatol 2013;32:1719-25.

13. Plasqui G, Boonen A, Geusens P, Kroot EJ, Starmans M, van der Linden S. Physical activity and body composition in patients with ankylosing spondylitis. Arthritis Care Res 2012;64:101-7.

14. Ramiro S, van Tubergen AM, Landewé R, Boonen A, Stolwijk C, Dougados M, et al. A physically demanding job may amplify the effect of disease activity on the development of syndesmophytes in patients with ankylosing spondylitis. Ann Rheum Dis 2014; 73:160-1.

15. Sieper J, Braun J, Rudwaleit M, Boonen A, Zink A. Ankylosing spondylitis: an overview. Ann Rheum Dis 2002;61 Suppl 3: iii8-18.

16. Sangha O, Stucki G, Liang MH, Fossel AH, Katz JN. The Self-Administered Comorbidity Questionnaire: a new method to assess comorbidity for clinical and health services research. Arthritis Rheum 2003;49:156-63.

17. Rabinovich RA, Louvaris Z, Raste Y, Langer D, Van Remoortel H, Giavedoni S, et al; PROactive Consortium. Validity of physical activity monitors during daily life in patients with COPD. Eur Respir J 2013;42:1205-15.

18. Troiano RP, Berrigan D, Dodd KW, Mâsse LC, Tilert T, McDowell M. Physical activity in the United States measured by accelerometer. Med Sci Sports Exerc 2008;40:181-8.
19. McHorney CA, Ware JE Jr, Raczek AE. The MOS 36-Item Short-Form Health Survey (SF-36): II. Psychometric and clinical tests of validity in measuring physical and mental health constructs. Med Care 1993;31:247-63.

20. Ware Jr JE, Kosinski M, Bayliss MS, McHorney CA, Rogers WH, Raczek A. Comparison of methods for the scoring and statistical analysis of SF-36 health profile and summary measures: summary of results from the Medical Outcomes Study. Med Care 1995;33 Suppl:AS264-79.

21. Calin A, Garrett S, Whitelock H, Kennedy LG, O'Hea J, Mallorie P, et al. A new approach to defining functional ability in ankylosing spondylitis: the development of the Bath Ankylosing Spondylitis Functional Index. J Rheumatol 1994;21:2281-5.

22. Garrett S, Jenkinson T, Kennedy LG, Whitelock H, Gaisford P, Calin A. A new approach to defining disease status in ankylosing spondylitis: the Bath Ankylosing Spondylitis Disease Activity Index. J Rheumatol 1994;21:2286-91.

23. Benjamini Y, Hochberg Y. Controlling the false discovery rate: a practical and powerful approach to multiple testing. J R Stat Soc Ser B Appl Stat 1995;57:289-300.

24. Ainsworth BE. How do I measure physical activity in my patients? Questionnaires and objective methods. Br J Sports Med 2009; 43:6-9.

25. Black A, Coward WA, Cole TJ, Prentice AM. Human energy expenditure in affluent societies: an analysis of 574 doubly-labelled water measurements. Eur J Clin Nutr 1996;50:72-92.

26. Plasqui G, Bonomi AG, Westerterp KR. Daily physical activity assessment with accelerometers: new insights and validation studies. Obes Rev 2013;14:451-62.

27. Davis JN, Hodges VA, Gillham MB. Physical activity compliance: differences between overweight/obese and normal-weight adults. Obesity 2006;14:2259-65.

28. Durcan L, Wilson F, Conway R, Cunnane G, O’Shea FD. Increased body mass index in ankylosing spondylitis is associated with greater burden of symptoms and poor perceptions of the benefits of exercise. J Rheumatol 2012;39:2310-4.

29. Atlantis E, Barnes EH, Ball K. Weight status and perception barriers to healthy physical activity and diet behavior. Int J Obes 2008;32:343-52.

30. Ball K, Crawford D, Owen N. Too fat to exercise? Obesity as a barrier to physical activity. Aust N Z J Public Health 2000;24:331-3.

31. Prince DS, McGuigan LE, McGirr EE. Working life and physical activity in ankylosing spondylitis pre and post anti-tumor necrosis factor-alpha therapy. Int J Rheum Dis 2014;17:165-72.

32. Ramiro S, Stolwijk C, van Tubergen A, van der Heijde D, Dougados $\mathrm{M}$, van den Bosch, et al. Evolution of radiographic damage in ankylosing spondylitis: a 12 year prospective follow-up of the OASIS study. Ann Rheum Dis 2015;74:52-9.

33. Ainsworth BE, Haskell WL, Whitt MC, Irwin ML, Swartz AM, Strath SJ, et al. Compendium of physical activities: an update of activity codes and MET intensities. Med Sci Sports Exerc 2000;32 Suppl:S498-504.

34. Zochling J, van der Heijde D, Burgos-Vargas R, Collantes E, Davis JC Jr, Dijkmans B, et al; 'ASsessment in AS' international working group; European League Against Rheumatism. ASAS/EULAR recommendations for the management of ankylosing spondylitis. Ann Rheum Dis 2006;65:442-52.

35. Sassen B, Cornelissen VA, Kiers H, Wittink H, Kok G, Vanhees L. Physical fitness matters more than physical activity in controlling cardiovascular disease risk factors. Eur J Cardiovasc Prev Rehabil 2009;16:677-83. 